\title{
O GÊNERO NECTANDRA ROL. EX ROTTB. (LAURACEAE) NO ESTADO DE PERNAMBUCO
}

\author{
Roxana Cardoso Barreto (1)
}

\begin{abstract}
RESUMO - O gênero Nectandra Rol. ex Rottb. foi estudado como parte do levantamento taxonômico da família Lauraceae no Estado de Pernambuco. Efetuaram-se coletas em diversas áreas, abrangendo todas as zonas fitogeográficas do referido Estado, durante o período de janeiro de 1982 a janeiro de 1984. Foram registradas duas espécies pertencentes ao gênero em estudo, constituindo primeira referência para o Nordeste do Brasil. Apresenta-se chave para as espécies estudadas com respectivas descriçōes, ilustraçōes e referências bibliográficas.
\end{abstract}

\begin{abstract}
The genus Nectandra Rol. ex Rottb. was studied as a part of the taxonomic survey of the family Lauraceae in the State of Pernambuco, Brazil. Collections were made in several areas, including all phytogeographic zones of that State, from January 1982 to January 1984. Two species of the genus in question were identified and are reported by the first time to the Northeastern Brazil. Key to species, descriptions, illustrations and bibliography references are reported.

Key-words: Lauraceae - Nectandra - Penambuco - Brasil
\end{abstract}

\section{Introdução}

O estudo do gênero Nectandra Rolander ex Rottböll faz parte de uma série de publicaçōes sobre os diferentes gêneros da familia Lauraceae Lindley que ocorrem no Estado de Pernambuco. Inicialmente foram apresentadas as novas-ocorrências de Lauraceae registradas no Estado de Pernambuco (Barreto 1985), acompanhadas por uma chave dicotômica para a identificação de todas as espécies relacionadas. Em seguida, o primeiro gênero a ser tratado separadamente foi Ocotea Aublet, que encontra-se descrito com suas respectivas espécies (Barreto 1987). Os demais gêneros serão posteriormente publicados.

A familia Lauraceae foi estudada no Estado de Pernambuco como objetivo inicial de um projeto mais amplo, pretendendo-se, no futcro, dar prosseguimento ao seu estudo taxonômico em outros Estados do Nordeste do Brasil.

A classificaçäo de Kostermans (1957) mostra-se como a mais atualizada classificação das Lauraceae e tem sido adotada por diversos autores. Entretanto, um aspecto de seu trabalho nāo foi aceito por alguns estudiosos da familia, tais como Bernardi (1962) e Allen (1966), que, discordando de Kostermans (1957) mantiveram separados os gêneros Ocotea, Nectandra e Pleurothyrium. Recentemente, Rohwer (1986) estudou os gêneros Ocotea, Nectandra, Pleurothyrium e Rhodostemonodaphyne, demonstrando que, apesar de existirem algumas formas intermediátias, estes gêneros podem ser reconhecidos distintamente. No estudo das Lauraceae de Pernambuco, a classificação da familia segue aquela de Kostermans (1957), embora Nectandra seja mantido com seu "status" genérico e considere-se as seç̧ōes indicadas por Rohwer (1986).

(1) Dept- Botâ.ica - CCB/UFPE. Av. Prof. Morais Rego S/N C.Universitária. CEP. 50.730 Recife-PE. BRASIL. 
Nees (1833) dividiu o gênero Nectandra Rol. ex Rottb. nos subgêneros Pomatia e Nectandra, descrevendo 10 espécies. Meissner (1864) apresentou o gênero com duas secções Pomatia e Porostema, descrevendo 75 espécies entre árvores e arbustos da América tropical e subtropical ao sul. Bentham \& Hooker (1880) enumeraram cerca de 70 espécies, sendo árvores ou raramente arbustos, ocorrendo na América Tropical, desde o Brasil e Peru até o México e Índias Ocidentais e América do Sul subtropical, distribuídas entre as secções Pomatia e Porostema. Mez (1889) definiu o gênero como constituído de árvores e arbustos da América tropical, numeroso na região andina, com poucos representantes no México e uma única espécie na Flórida, com algumas outras dispersas pela

Argentina e Paraguai. Descreveu 77 espécies, distribuídas entre os subgêneros Synandrodaphne Meissn., de flores díclinas, e Eunectandra Mez, de flores monóclinas, sendo o segundo subdividido nas secções Pomatia Nees e Porostema Schreb. A secçãc Pomatia, segundo o referido autor, difere da secção Porostema por apresentar flores com diâmetro maior, sem estaminódio e base da margem foliar menos revoluta. Pax (1894) dividiu Nectandra nas secções Pomatia e Porostema, enumerando 70 espécies distribuídas na América do Sul subtropical e na América tropical desde o Brasil até o norte do Peru, aparecendo ainda no México. Bernardi (1962), descreveu o gênero como árvores ou arbustos da América tropical e subtropical, aceitando a classificação de Mez (1889) e apresentando 25 espécies da Venezuela e países vizinhos, com respectivas diagnoses, distribuição e comentários. Rohwer (1986) caracterizou Nectandra não apenas pela posição dos locelos nas anteras, mas também pelo indumento floral; dividiu o gênero nas secções Pomatium e Nectandra.

No Estado de Pernambuco, foram encontradas duas espécies pertencentes ao gênero Nectandra: Nectandra membranacea ssp. cuspidata (Nees)Rohwer e Nectandra cissiflora Nees, ambas da secção Nectandra, segundo Rohwer (1986).

\section{Material e Métodos}

Foram analisadas exsicatas da familia Lauraceae encontradas em herbários locais, bem como em diversos herbários de outros Estados brasileiros e do exterior, relacionados a seguir: Herbário da Empresa Pernambucana de Pesquisa Agropecuária (IPA), Herbário "Vasconcelos Sobrinho" da Universidade Federal Rural de Pernambuco (PEUFR), Herbário "Sérgio Tavares" da Fundação Instituto Tecnológico do Estado de Pernambuco (HST), Herbário do Departamento de Botânica da Universidade Federal de Pernambuco (UFP), Herbário e Xiloteca do Departamento de Recursos Naturais da Superintendência do Desenvolvimento do Nordeste (HDBE), Herbário do Jardim Botânico do Rio de Janeiro (RB), Herbário do Instituto de Botânica de São Paulo (SP), Herbário do Departamento de Botânica do Instituto de Biociências da Universidade Federal do Rio Grande do Sul (ICN), Centro de Pesquisa Agropecuária do Trópico Úmido (IAN), Departamento de Ecologia da Universidade Federal da Paraíba (JPB), Coordenação do Meio Ambiente de Alagoas (MAC), Departamento de Botânica da Universidade Federal de Sergipe (ASE), Centro de Pesquisas do Cacau, Bahia (CEPEC), Universidade Federal de Viçosa, Minas Gerais (VIC), Departamento de Biologia Vegetal da Universidade de Brasnia (UB), Instituto de Biociências da Universidade de São Paulo (SPF) e Field Museum of Natural History, Chicago, USA (F).

Além do material herborizado, foram observados exemplares em seu ambiente natural, sendo os mesmos também coletados e incorporados às coleções do Herbário da Empresa Pernambucana de Pesquisas Agropecuária (IPA) e do Herbário "Vasconcelos Sobrinho" da UFRPE. Foram realizadas 26 viagens de coleta no përíodo de janeiro de 1982 à janeiro de 1984, abrangendo municípios de diferentes áreas fitogeográficas do Estado de Pernambuco, delimitadas de acordo com Lima (1960). 
O trabalho foi desenvolvido conforme os métodos convencionais utilizados em estudos taxonômicos, sendo o gênero Nectandra e as respectivas espécies descritos com base no material de Pernambuco.

Com o objetivo de tornar mais fácil o estudo das folhas, quanto à nervação, foi necessário diafanizá-las, tomando como base o método de diafanização proposto por Etting shausen (1861). Contudo, para a classificação da arquitetura das folhas seguiu-se a orientação do trabalho de Hickey (1973).

\section{Resultados e Discussão}

\section{Nectandra Rolander ex Rottböll}

Acta Litt. Hafn. 1: 279. 1778.

Árvores. Ramos terminais subcilíndricos a angulosos. Folhas alternadas, de lâmina elíptica, ovóide a lanceolada, cartáceo-coriácea, com venação pinada camptódroma eucamptódroma ou broquidódroma. Inflorescências em panículas axilares laterais e subapicais. Flores monóclinas, trímeras, alvas e cremes, freqüentemente perfumadas; hipanto evidente a praticamente nulo; perigônio com 6 tépalas em dois verticilos, patentes. Androceu com 9 estames férteis em três verticilos; anteras tetralocelares, as do primeiro e segundo verticilos com locelos dispostos em arco, de deiscência introrsa, as do terceiro verticilo com locelos sobrepostos, os superiores lateralmente extrorsos, os inferiores extrorsos a lateralmente extrorsos; nectários estaminodiais sésseis, basais ou anexos aos estames do terceiro verticilo, estaminódios do quarto verticilo presentes. Gineceu com ovário súpero, ovóide a arredondado, estilete com 0,1-0,8 mm de comprimento, estigma truncado ou trígono comprimido. Fruto baga globosa a oblonga, exserta da cúpula, de margem simples.

Chave para identificação das espécies do gênero Nectandra em Pernambuco:

1.a. Folhas com nervuras terciárias perpendiculares em relação à principal; hipanto evi-

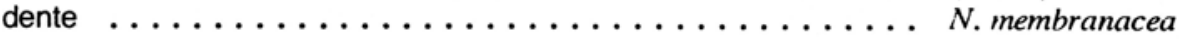

1.b. Folhas com nervuras terciárias obliquas em relação à principal; hipanto praticamente



Nectandra membranacea ssp. cuspidata (Nees) Rohwer Prod. Monographie 72. 1986.

Figuras 1 a 8.

Basiônimo:

Nectandra cuspidata Nees et Martius ex Nees Syst. Laurinarum 330. 1836.

Árvore de 8-10 m de altura. Ramos angulosos a subcilíndricos no ápice, de córtex castanho, ferrugíneo e tomentoso nas partes terminais. Folhas com pecíolo sulcado ventralmente, medindo 0,5-1,3 cm de comprimento. Lâmina elíptica, ovóide a lanceolada, cartáceo-coriácea, com base aguda, ápice em geral longamente acuminado, margem revoluta na base, face adaxial pubérula, face abaxial pubescente, de coloração mais escura, tendendo a subglabra nas duas faces com o envelhecimento, venação pinada comptódroma eucamptódroma com nervuras principal e secundárias imersas na face superior e proeminentes na face inferior, nervuras terciárias perpendiculares à nervura principal, geralmente pouco visíveis em ambas as faces, 9,7-19,5 cm de comprimento e 2,9-5,3 cm de largura. 
Inflorescências em panículas axilares laterais a subapicais, com pequenos ramos, muito abertos, de duas a três divisões e râmulos em geral com três flores, com raque pubescente, de 6-11 cm de comprimento. Brácteas elípticas, de ápice agudo, caducas, cerca de $2 \mathrm{~mm}$ de comprimento. Bractéolas caducas. Flores cremes, pubescentes, com 6,5 $\mathrm{mm}$ de comprimento e 3,5 mm de diâmetro. Pedicelos pubescentes, com 4,5 mm de comprimento. Hipanto evidente, tépalas patentes, ovóides, de ápice obtuso, $2 \mathrm{~mm}$ de comprimento e 1 $\mathrm{mm}$ de largura. Androceu com estames de cerca de $1 \mathrm{~mm}$ de comprimento, filetes muito curtos, cerca de $0,2 \mathrm{~mm}$ de comprimento; primeiro e segundo verticilos com anteras arredondadas, deiscência introrsa, locelos dispostos em arco, terceiro verticilo com anteras retangulares, locelos lateralmente extrorsos, com nectários estaminodiais anexos, sésseis. Estaminódios subtriangulares, com ápice obtuso, 0,5 mm de comprimento. Gineceu glabro, com $1 \mathrm{~mm}$ de comprimento, ovário ovóide, estilete curto, grosseiro, estigma trígono, comprimido. Fruto globoso, exserto da cúpula, com $1 \mathrm{~cm}$ de diâmetro; cúpula obcônica, de margem simples.

\section{Material Examinado:}

Pernambuco: Rio Formoso, Saltinho, Campo do IBDF, 15.03.1969, G.H. Carvalho 135 (HST 2816); Rio Formoso, Fazenda Bom Jardim, mata, 28.05.1971, D. Andrade-Lima 71-6251 (IPA 24359): Amaraji, Engenho Trindade, capoeira no caminho para a mata da Encrenca, 07.12.1983, Roxana Barreto, Alda Chiappeta e Rita Lima, CFPE 843 (IPA 31972); Caruaru, Fazenda Caruaru, Sitio do Abacate, 09.11.1983, Roxana Barreto, V.C.Lima e Rita Lima, CFPE 739 (IPA 31701); Caruaru, Fazenda Caruaru, Sítio do Abacate, na capoeira, 09.11.1983, Roxana Barreto, V.C. Lima e Rita Lima, CFPE 740 (IPA 31702); Brejo da Madre de Deus, Propriedade Bituri, 05.02.1965, D. Andrade-Lima 65-4303 (IPA 13666); Brejo da Madre de Deus, Propriedade Bituri, borda da capoeira, na subida para a mata da Pontaria, 20.08.1980, Ana Perruci e M.A. Maia Filho 15 (IPA 25928); Brejo da Madre de Deus, Propriedade Bituri, Sítio Caçanje, capoeira na subida para São Gonçalo, 10.11.1983, Roxana Barreto, V.C.Lima e Rita Lima, CFPE 774 (IPA 31953); Brejo da Madre de Deus, Sítio Pontaria, 10.11.1983, Roxana Barreto, V.C. Lima e Rita Lima, CFPE 778 (IPA 31954); Brejo da Madre de Deus, Sítio Pontaria, à borda da mata, na estrada para Santa Rosa, 10.11.1983, Roxana Barreto, V.C. Lima e Rita Lima, CFPE 780 (IPA 31955). Amazonas: Manaus, Cachoeira Grande, 03.03.1882, Schwacke 3537 (RB 48711); Barcellos, Rio Negro, 09.06.1905, A. Ducke, Herb. Amaz. 7085 (RB 17581). Pará: Cachoeira do Mangabal, Rio Tapajoz, 15.12.1919, A. Ducke (RB 11370), Belém, Entroncamento, Capoeira Velha, terra firme, 27.05.1926, A. Ducke (RB 19939); Belém, 12.11.1955, J.M. Pires e G.A. Black 594 (SP 81357); Cuminá-mirim, Rio Cuminá, Repartimento, Capoeira da Várzea, 19.01.1968, M. Silva 1232 (SP 110339). Ceará: Serra do Baturité, Sítio Caridade, 21.09.1939, José Eugênio 562 (RB 44676); Crato, mata úmida da encosta da Serra do Araripe, 27.06.1952, D. Andrade-Lima e M. Magalhães 52-119 (IPA 5346); Encosta alta da Serra de Pacatuba, Sítio Pitaguari, mata, 16.02.1968, D. Andrade-Lima 68-5258 (IPA 16456). Mato Grosso: Barra do Garças, próxima à fonte de água quente, 10.04.1958, D. Andrade-Lima 58-3031 (IPA 11602). Rio de Janeiro: Sacopã, 12.03.1946, Aparício e C.T. Rizzini 42 (SP 81359); Rio de Janeiro, estrada da Vista Chinesa, junto à Estação Biológica, 13.03.1963, J.P. Lanna Sobrinho 567 (SP 99672). São Paulo: Itha do Cardoso, mata, 21-23.02.1981, K. Kubitzki, A. Custódio Filho, M. Motidome e E. Lopes 81-33 (SP 169722). Paraná: Morretes, Estação Morumbi, em mata pluvial tropical da Serra do Mar, 20.03.1947, G. Hatschbach (SP 54740). Santa Catarina: Itajaí, Morro da Fazenda, mata, 04.03.1954, Reitz e Klein 1695 (SP 113989); Itajaí, Cunhas, mata, 14.04.1955, R.M. Klein 1296, (SP 113991); Itajal, Braço Joaquim, Luíz Alves, mata, 16.11.1956, Reitz e Klein 2682 (SP 113993); Blumenau, Bom Retiro, mata da Companhia Hering, 05.02.1960, Reitz e Klein 9521 (SP 113992). 


\section{Comentários:}

Nectandra membranacea ssp. cuspidata (Nees) Rohwer tem sido bastante confundida com $N$. pichurim (H. B. K) Mez, devido à forma de suas folhas e venação, além de apresentarem o ovário imerso no hipanto. Diferem, contudo, nos frutos, que na segunda espécie, segundo Kostermans (1936), apresentam cúpula subpateriforme, rugosa e de margem dupla, enquanto, na primeira espécie, a cúpula tem forma de prato e margem simples. Contudo, Rohwer (1986) considerou N. pichurim (H. B. K) Mez sinônimo de N. membranacea ssp. cuspidata (Nees) Rohwer.

Quanto ao porte, o exemplar coletado no Mato Grosso por D. Andrade-Lima 58-3031 é referido como árvore de 4-6 m, enquanto no Ceará, na encosta alta da Serra de Pacatuba, Sítio Pitaguari, D. Andrade-Lima 68-5258 a encontrou com 20 m de altura.

Encontra-se freqüentemente em serras, nos brejos de altitude, e locais próximos a bacias fluviais. Apresenta larga distribuição no território brasileiro, ocorrendo em alguns Estados desde o Amazonas até Santa Catarina. Meissner (1866) referiu a espécie para os Estados do Amazonas, Mato Grosso, Rio de Janeiro e, fora do Brasil, para Guiana, Suriname, Panamá e Ilhas de Guadalupe. Rohwer (1986) citou o Estado da Amazonas como área de ocorrência, mencionando localidades ao longo das margens do Rio Amazonas. Em Pernambuco, até o presente, foi encontrada em quatro municípios: Rio Formoso, Amaraji, Caruaru e Brejo da Madre de Deus.

De acordo com a localidade, é conhecida por diferentes nomes vulgares, tais como: "louro-canela" ou "louro-pimenta", em Pernambuco, "louro-preto", no Pará; "louro" no Ceará, "canela", no Rio de Janeiro e "canela-branca", em Santa Catarina.

Nectandra cissiflora Nees Syst. Laurinarum 296. 1836.

Figuras 9 a 16.

Sinônimo:

Nectandra myriantha Meissner Prod. Syst. Nat. 15 (1): 163.1864.

Árvore com cerca de $20 \mathrm{~m}$ de altura e $35 \mathrm{~cm}$ de diâmetro na base do tronco. Ramos subcilindricos e tomentosos nas partes terminais, de córtex castanho. Folhas com peciolo sulcado ventralmente, medindo $1,2-2,2 \mathrm{~cm}$ de comprimento. Lâmina elíptica, cartáceo-coriácea, com base obtusa, ápice levemente acuminado, face adaxial pubérula a subglabra, face abaxial pubescente, venação pinada camptódroma broquidódroma, com nervuras principal e secundárias imersas na face superior e proeminentes na face inferior, nervuras terciárias oblíquas à nervura principal, quase imperceptíveis em ambas as faces, 6,8-11,1 cm de comprimento e 3,9-5,9 de largura. Inflorescências em panículas axilares laterais e subapicais, multifloras, com raque pubescente, com cerca de $22 \mathrm{~cm}$ de comprimento. Brácteas muito estreitas, caducas, cerca de $0,5 \mathrm{~mm}$ de comprimento. Flores alvas, pubérulas, com 3,5 mm de comprimento e $3 \mathrm{~mm}$ de diâmetro. Pedicelos pubérulos, com $2 \mathrm{~mm}$ de comprimento. Hipanto praticamente nulo, Tépalas patentes, ovóides, de ápice obtuso, $1,5 \mathrm{~mm}$ de comprimento e $1 \mathrm{~mm}$ de largura. Androceu com estames de cerca de 0,5 $\mathrm{mm}$ de comprimento, filetes curtos, cerca de $0,1 \mathrm{~mm}$ de comprimento; primeiro e segundo verticilos com anteras suborbiculares, deiscência introrsa, locelos dispostos em arco, terceiro verticilo com anteras subtriangulares, locelos superiores lateralmente extrorsos e inferiores extrorsos, com nectários estaminodiais sésseis, globosos. Estaminódios subtriangulares, com ápice agudo, 0,3 mm de comprimento. Gineceu glabro, com $1 \mathrm{~mm}$ de comprimento, ovário arredondado, estilete muito curto, estigma truncado. 


\section{Material Examinado:}

Pernambuco: Vicência, mata do Engenho Jundiá, córrego do Cabatan, 17.11.1962, S. Tavares 1140 (HST 1149). Goiás: 48 Km ao sul de Caiapônia, floresta, 25.10.1964, G. T. Prance e N.T. Silva 59635 (UB 59746); Serra do Caiapó, floresta de galeria, cerca 45 km ao sul de Caiapônia, estrada para Jatár, elevação de 900 m, 28.06.1966, H.S. Irwin, R. Souza, J.W. Grear, R. Reis dos Santos 17915 (UB 33786); Luziânia, 80 km de Brasnia, na beira do córrego, mata ciliar, 20.07.1973, E.P. Heringer 12845 (UB 33785); próximo à Goiás Velho, em remanescentes de floresta semidecídua no vale de um rio, 05.09.1976, J.A. Ratter 3552 (UB 59744). Distrito Federal: Brasnia, Fundação Zoobotânica, mata, 23.05.1961, E.P. Heringer 8380 (UB 59729); Brasnia, Horto do Guará, mata, 26.05.1961, E.P. Heringer 8388/582 (RB 128866); Brasilia, Fundação Zoobotânica, brejo à margem da mata, 12.06.1961, E.P. Heringer 8423 (UB 59745); Brasnia, salda sul, córrego Vicente Pires, mata ciliar, 23.04.1963, J.M. Pires, N.T. Silva e R. Souza 9287 (UB 59851); Brasnia, córrego Vicente Pires, salda sul, mata ciliar, 25.06.1964, J.M. Pires 58062 (UB 59749); Brasnia, Country Club, floresta ao lado da estrada 22.07.1965, R. Martin, 463 (UB 59747); Parque Nacional, mata da Barragem Santa Maria, 24.06.1970, Sidney G. Fonseca 1622 (UB 59750); Brasnia, Córrego da Papuda, 13.08.1981, J. Elias de Paula 1491 (UB 62579). São Paulo: Catanduva, 24.08.1941, A. Gehrt (UB 33835). Brasil. Pohl s/n (M) C.N.H.M. 19267 (Fotografia do material). Brasil, Riedel 2440 (C) C.N.H.M. 22069 (Fotografia do material).

\section{Comentários:}

Rohwer (1986) considerou Nectandra myriantha Meissn., nome usado anteriormente por outros autores, sinônimo de $N$. cissiflora Nees.

A exsicata de S. Tavares 1140 é a única coleta desta espécie para o Estado de Pernambuco. O material em questão não é completo e consta somente de ramos com flores, sendo as últimas referidas como alvas e perfumadas. Daí foram obtidos os dados relativos ao porte da árvore. Recentemente houve uma nova exploração no mesmo local, na tentativa de obter-se o material mais completo e principalmente com frutos, o que não foi possivel, valendo ressaltar o grande desmatamento ocorrido durante as duas últimas décadas para o cultivo da cana-de-açúcar (Saccharum officinarum L.) naquela localidade.

Os frutos desta espécie puderam ser observados na coleta de G.T. Prance e N.T. Silva 59635, que os descreveram como negros, quando maduros. São bagas oblongas, exsertas, com $1,5 \mathrm{~cm}$ de comprimento e $0,8 \mathrm{~cm}$ de diâmetro, em cúpula de margem simples, em forma de prato.

De acordo com o material observado para os outros Estados, constata-se variação na forma e comprimeto das folhas. Estas folhas podem apresentar-se com lâminas elípticas a obovais, podendo sua base ser aguda e o ápice mais fortemente acuminado, alcançando $27 \mathrm{~cm}$ de comprimento e $11 \mathrm{~cm}$ de largura. Um caráter citado por Meissner (1866) como diferencial, mas nem sempre facilmente evidenciado, é a margem revoluta na base.

A espécie em questão, ao que tudo indica, apresenta grande potencial como árvore ornamental, pela beleza de suas panículas, com o eixo alongado e muito florido. E.P. Heringer 12845 observa que seus frutos servem de alimento aos pássaros e outros animais, sendo sua madeira utilizada em serrarias. Segundo Corrêa (1926), fornece ótima madeira de cor amarelada, muito resistente à umidade, própria para construção naval, obras externas, marcenaria e dormentes de primeira classe.

Parece habitar quase sempre em locais próximos à corrégos ou rios. Além do material estudado, há registros de sua ocorrência, de acordo com Meissner (1866), nos Estados de Minas Gerais e São Paulo, sendo a espécie referida também em São Paulo, por Coe-Teixeira (1967). Rohwer (1986) mencionou a espécie para o Brasil. No Estado de Pernambuco, foi encontrada apenas no município de Vicência, na Zona da Mata Norte, onde é conhecida como "louro-babão". 




Nectandra membranacea ssp. cuspidata (Nees) Rohwer. (IPA 31955).

1 - Ramo. 2 - Botão em vista lateral. 3 - Estame do $1^{\circ}$ e $2^{\circ}$ verticilos, com locelos introrsos, dispostos em arco. 4 - Estame do $3^{\circ}$ verticilo, com locelos lateralmente extrorsos, com nectários estaminodiais anexos, sésseis. 5 - Estaminódio do $4^{\circ}$ verticilo. 6 - Pistilo. 7 - Diagrama floral. 8 - Diagrama esquemático da flor em seção longitudinal: a) hipanto; b) tépalas do $1^{\circ}$ e $2^{\circ}$ verticilos, externos (séries I e II); c) estames do $1^{\circ}$ e $2^{\circ}$ verticilos, externos opostos às tépalas; d) nectários estaminodiais anexos ao estames do $3^{\circ}$ verticilo, interno; e) estames do $3^{\circ}$ verticilo, interno (série III); f) estaminódios do $4^{\circ}$ verticilo, interno (série IV). 

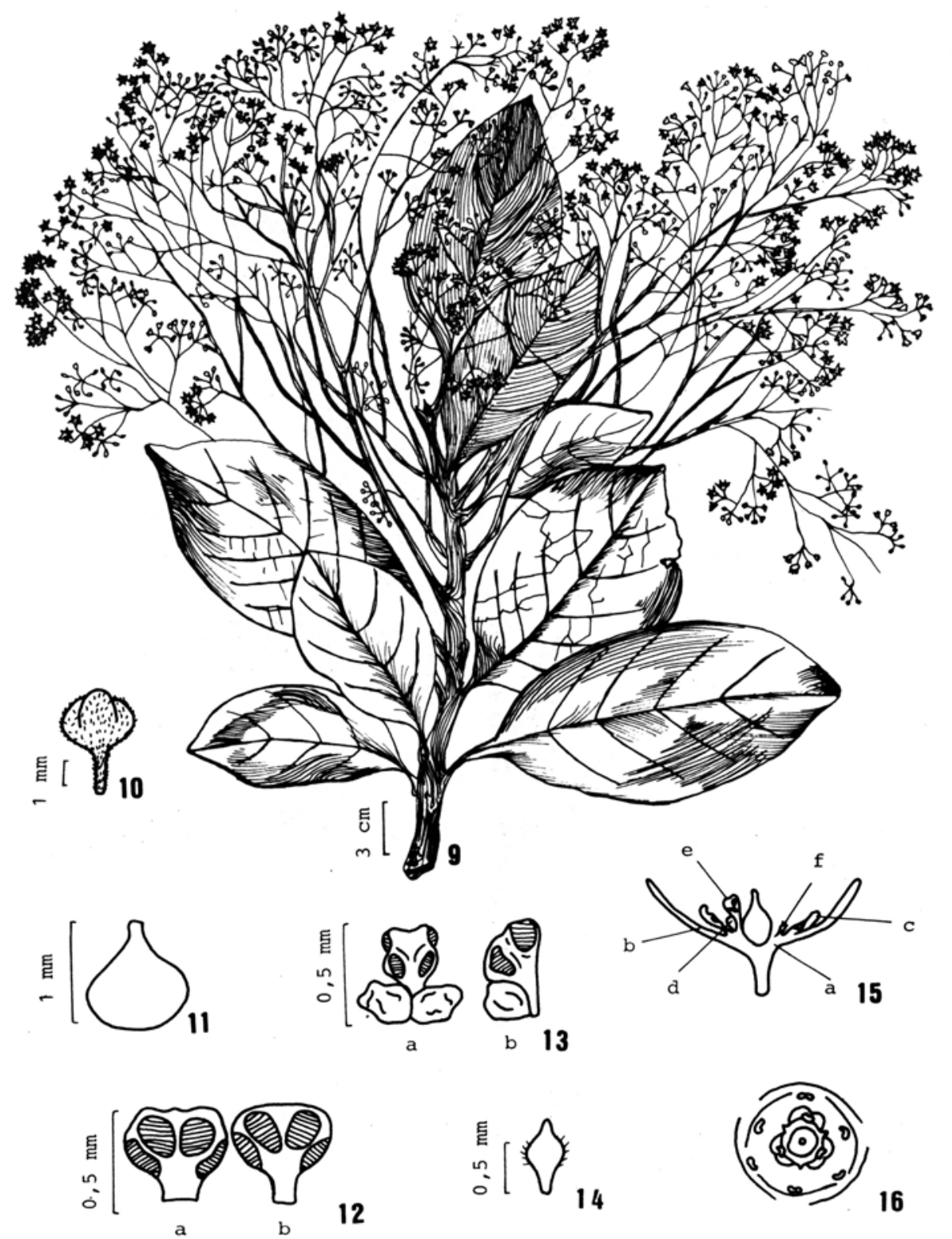

Nectandra cissiflora Nees. (HST 1149).

9 - Ramo. 10 - Botăo em vista lateral. 11 - Estames: a) estame do $1^{\circ}$ verticilo, com locelos introrsos, dispostos em arco; b) estame do $2^{\circ}$ verticilo, com locelos introrsos, dispostos em arco. 12) Estame do $3^{\circ}$ verticilo: a) estame em vista frontal, com locelos superiores lateralmente extrorsos, inferiores extrorsos, com nectários estaminodiais basais, globosos, sésseis; b) estame em vista lateral. 13 - Estaminódio subtriangular do $4^{\circ}$ verticilo. 14 - Pistilo. 15 - Diagrama floral. 16 - Diagrama es juemático da flor em seção longitudinal: a) hipanto; b) tépalas do $1^{\circ}$ e $2^{\circ}$ verticilos, externos (séries le II); c) estames do $1^{\circ}$ e $2^{\circ}$ verticilos, externos, opostos às tépalas; d) nectários estaminodiais basais do $3^{\circ}$ verticilo de estames: e) estames do $3^{\circ}$ veticilo, interno (série III); f) estaminódios do $4^{\circ}$ verticilo interno (série IV). 


\section{Referências Bibliográficas}

ALLEN, C.K. 1966. Notes on Lauraceae of tropical América: I The generic status of Nectandra, Ocotea and Pleurothyrium. Phytologia 13 (3): 221-31.

BARRETO, R.C. 1987. O gênero Ocotea Aubl. (Lauraceae) no Estado de Pernambuco. In: Anais do XXXVI Congresso Nacional de Botânica, Curitiba, 1985. (entregue para publicaçāo).

BARRETO, R.C. 1985. Novas ocorrências de Lauraceae no Estado de Pernambuco. In: Anais do VIII Reunião Nordestina de Botânica, Recife, 1984. p. 109-116.

BENTHAM, G. \& HOOKER, J.D. 1880. Genera plantarum. London, Reeves, v.3.

BERNARDI, L. 1962. Lauráceas. Merida, Universidad de los Andes, Fac. de Ciencias Florestales. 355 p.

COE-TEIXEIRA, B. 1967. Lauráceas do Estado de São Paulo III. Nectandra. In: Anais do XV Congresso Brasileiro de Botânica, Porto Alegre, p. 119-23.

CORREA, M.P. 1926. Dicionário de plantas úteis e medicinais do Brasil. Rio de Janeiro. Imprensa Nacional. v. 1-6.

ETTINGSHAUSEN, C. von. 1861. Die Blattskelete des Dicotyledonen. Viena, K.K. Hof. Staatsdruckerei.

HICKEY, L.J. 1973. Classification of the architecture of Dicotyledonous leaves. American Journal of Botany, 60 (1): 17-33.

KOSTERMANS, A.J.G.H. 1936. Revision of the Lauraceae I. Mededeelingen van het Botanisch Museum en Herbarium van de Rijks - universiteit, Utrecht, 37: 719-757.

KOSTERMANS, A.J.G.H. 1957. Lauraceae. Reinwardtia 4(2): 193-256.

LIMA, D. de A. 1960. Estudos fitogeográficos de Pernambuco. Arquivos do IPA, Recife, 5: $305-41$.

MEISSNER, C.F. 1864. Lauraceae. In A. de Candolle (ed.) Prodromus Systematis naturalis regni vegetabile. Paris, Victoris Masson et Filii. 15 (1): 1-260.

MEISSNER, C.F. 1866. Lauraceae. In C.F.D. Martius (ed.) Flora brasiliensis. Monachii, Typographia Regia. 5 (2): 137-320.

MEZ, C. 1889. Lauraceae americanae. Berlin, Gebrüder Borntraeger. 556p.

NEES, C.G. 1833. Revisio Laurinarum. Linnaea. 8: 36-51.

PAX, F. 1894. Lauraceae. In A. Engler \& K. Prantl (eds.) Die Natürlichen pflanzenfamilien. Leipzig, Verlag von Wilhelm Engelmann, 1 (1): 106-26.

ROHWER, J.G. 1986. Prodromus einer monographie der Gattung Ocotea Aubl. (Lauraceae) sensu lato. Hamburg. Hubert \& Co. 278 p. 